\title{
Values, Susceptibility to Normative Influence, and Attribute Importance Weights: A Nomological Analysis
}

\author{
Rajeev Batra \\ School of Business Administration \\ University of Michigan \\ Pamela M. Homer \\ College of Business Administration \\ California State University, Long Beach \\ Lynn R. Kahle \\ Department of Marketing \\ University of Oregon
}

\begin{abstract}
It is argued that the construct of individual susceptibility to normative influence (SNI) needs to be put into a wider nomological framework, with antecedents and consequences. Based on prior literature, a causal sequence is hypothesized in which values are antecedent to SNI, which itself shapes the importance placed by the individual on different attributes. It is further suggested that the relation between values and SNI is strongest for "external" values, and that high SNI leads to greater importance for attributes that provide "socially visible" benefits. Data from a national field survey $(N=663)$ on consumer preferences are analyzed to test these hypotheses, using confirmatory factor analysis via LISREL 8.30 (Jöreskog \& Sörbom, 1993). The analysis finds support for most of the hypothesized structural relations.
\end{abstract}

A quarter of a century after Rokeach (1973) stated that the most important construct in social science is values, the construct continues to inspire research and to receive attention from significant scholars (e.g., Seligman, Olson, \& Zanna, 1996). Rokeach viewed values as core motivations, as cognitive transformations of basic psychological needs; thus, values should have implications for a variety of content domains. In consumer psychology, consumer values ought to help us understand why consumers choose particular brands, why some teenagers begin consuming cigarettes and illegal drugs, and why some adults want to consume conspicuously or in ways that contribute mightily to ecological and social problems. A variety of methodological approaches have been applied to value research, ranging from restricted-sample surveys (e.g., Feather, 1993; Homer \& Kahle, 1988) to

Requests for reprints should be sent to Rajeev Batra, D6212 Business Administration, University of Michigan, Ann Arbor, MI 48109. E-mail: rajeevba@umich.edu large-scale surveys (e.g., Kahle, 1983; Rokeach, 1973) and from carefully controlled laboratory experiments (e.g., Kristiansen \& Zanna, 1992; Lydon \& Zanna, 1990) to grand-scale field experiments (e.g., Ball-Rokeach, Rokeach, \& Grube, 1984). After reflecting on this research, Feather (1996) noted significant progress has been made but concluded that more could be done, especially in relation to basic questions such as relations between the general values that people hold and their more specific attitudes, and between these values and behaviors.

Accordingly, we examine in this article how the values construct can contribute to building a "nomological network" (Cronbach \& Meehl, 1955) for another important construct, an individual's susceptibility to normative influence (SNI) from reference groups (Bearden, Netemeyer, \& Teel, 1989, 1990). As the literature review discussed later indicates, prior research on this important SNI construct (with a few exceptions) usually has examined normative influence effects in relative theoretical isolation. With the objective of extending the nomological network for this construct, this article exam- 
ines how different dimensions of values affect SNI and how SNI then relates to one set of behavior consequences (the importance placed by consumers on different product attributes). We use data from a national field sample, which asked questions on values and attribute importance weights, and used items demonstrably similar (but not identical) to Bearden et al.'s (1989) SNI scales.

\section{SNI}

Numerous researchers have examined the impact of social groups on individual behaviors, especially choices among alternatives (see Bearden \& Etzel, 1982, for an excellent review of this phenomenon in the consumer research literature). These studies showed that choices in various information-processing situations are susceptible to the influence of reference groups, defined as groups, used as standards of comparison for self-appraisal or as a source of personal norms and attitudes.

One stream of research on reference group influence examined the dimensionality of such influence (e.g., "informational," where low-knowledge consumers seek information from perceived experts; "utilitarian," compliance to gain rewards or avoid punishments; and "value-expressive," where consumers identify with a group to enhance their self-image and ego; cf. Katz, 1960). More recent research collapsed the utilitarian and value-expressive categories into a single "normative" category, based on empirical difficulties in establishing discriminant validity among the former (Bearden et al., 1989).

A second stream of consumer research focused on variables that moderate the effects of reference group influence. Many researchers have argued that reference group effects are stronger when the product category is more "conspicuous," such as by being a scarce luxury good or by being one whose ownership or consumption are publicly visible (Bearden \& Etzel, 1982). It has also been suggested that reference group effects will be stronger for certain more influenceable individuals, through an individual difference construct called the susceptibility to interpersonal influence (cf. McGuire, 1968). Bearden et al. (1989) reported the construction of two scales to measure two dimensions of such interpersonal influenceability, normative (combining value-expressive and utilitarian) and informative. Our study examines only the normative dimension, through the SNI construct.

\section{SOCIAL VALUES}

Values are conceptualized as enduring beliefs that individuals hold about what specific modes of conduct, or end-states, they believe are more important (Rokeach, 1973). They have also been defined as cognitive representations of universal human requirements, both biological and social (Schwartz \&
Bilsky, 1987), and as the "guiding principles in an individual's life" (Schwartz, 1992, p. 17). As a consequence, values are assumed to be the most abstract form of social cognition, serving to facilitate adaptation to one's environment (Kahle, 1983, 1996). In particular, they are conceptualized as being shaped largely by pre-adult socialization and are seen as more general, more situationally invariant, and more stable and enduring than other situation-dependent predispositions (Schwartz, 1992), of which SNI is one (McGuire, 1968). This reasoning suggests that values ought to be causally antecedent to a predisposition such as SNI (cf. Stern, Dietz, Kalof, \& Guagnano, 1995). Consistent with this reasoning, various studies supported the hierarchical primacy of values over attitudes and behaviors (e.g., Homer \& Kahle, 1988).

It might be argued that SNI itself represents the degree to which an individual seeks compliance, and that SNI could precede compliance-related values (instead of the other way around), or that both could be caused by some third construct. Three arguments can be made against such rival causal sequences.

First, as just discussed, values are commonly conceptualized as being the most general, abstract, and enduring kind of social cognition, formed very early during childhood (Dietz \& Stern, 1995; Feather, 1975; Miniard \& Cohen, 1979; Stern et al., 1995), and should therefore logically come first because of their earlier emergence.

Second, cognitive constructs that are more "general" or "situationally invariant" should causally precede those that are "less general" and more "situationally variable." In the description of the expected relations between beliefs, attitudes, and intentions, for instance, Ajzen and Fishbein (1980) argued that the beliefs that underlie attitudes potentially apply to several attitude objects (thus being most general), with the resulting attitude toward that object being more specific, and any attitude toward an act concerning that object being even more situation-specific (requiring time and place specifications). As an example, a belief that "fighting cavities is a good thing" is obviously more general (because it applies to any toothpaste) than a favorable attitude to Crest toothpaste specifically, because it is believed to fight cavities well, which is itself more general than a favorable attitude toward using Crest toothpaste at a certain time and place. Theory and evidence suggest that although values are quite general, SNI is more situation-specific. Schwartz (1992) argued that "conformity values"- similar to the "compliance-creating" values of Rokeach (1973) discussed previously - have the motivational goal of the "restraint of actions, inclinations, and impulses likely to upset or harm others and violate social expectations or norms" (p. 9) and lead to a multiplicity of consequent actions, including obedience, politeness, honoring parents, self-discipline, and so forth. Such multiple consequences give these values considerable generality. In contrast, although SNI is conceptualized as the degree of individual influenceability applying across situations (Bearden et al., 1989; McGuire, 1968), it is also recognized by McGuire to be only a "weak trait" (p. 1132), because 
its intercorrelations across situations and behaviors are quite low. Fishbein and Ajzen (1975) and others (e.g., Bearden \& Etzel, 1982; Bourne, 1957) have also pointed out that the effect of normative considerations on behavior may vary for the same person depending on situational variables such as the behavior's observability. Thus, values, being more general, should precede SNI, which is more situation-dependent. Joachimsthaler and Lastovicka (1984), citing Allport (1961), and Eysenck (1967), argued that personality-like traits can be viewed as operating hierarchically: A few fundamental traits (here, values) can influence a larger set of central or intervening traits (here, SNI) which then influence a much larger set of secondary traits or dispositions operant only in limited settings or roles (here, attribute weights for clothing). Our model is such a hierarchical trait model.

Third, in his extensive review of the literature on "influenceability" (which Bearden et al., 1989, used as the theoretical inspiration for SNI), McGuire (1968) at various places characterized influenceability as a consequence of, and as being dependent on, personality variables such as self-esteem or anxiety; for example, "... the lack of self-esteem should make (a person) more influenceable" (p. 1155). Such a causal effect of self-esteem on influenceability was also discussed by Cox and Bauer (1964) and Janis (1954; cf. Bearden et al., 1989). As we have already stated, values have been conceptualized as "the guiding principles in an individual's life" by Schwartz (1992, p. 17) and as the most abstract form of social cognition, serving to facilitate adaptation to one's environment (Kahle, 1983). They are thus fundamental, as is self-esteem. In contrast, we stated previously that SNI (and influenceability) is seen as being a situation-dependent predisposition, because its intercorrelations across situations and behaviors are quite low (McGuire, 1968) and because the effect of normative considerations on behavior may vary for the same person depending on situational variables such as the behavior's observability (Bearden \& Etzel, 1982). Thus, because values like self-esteem are fundamental self-cognitions that guide a multiplicity of behaviors, and SNI is more situationally variable in its consequences, values too should precede susceptibility to social influence. Causal tests supporting the precedence of self-esteem over susceptibility to social influence, using cross-lagged panel correlations, have been reported by Kahle, Kulka, and Klingel (1980).

All these perspectives imply that if individuals are susceptible to interpersonal influence (for any reason, informative or normative), such susceptibility should be derived from (and thus, be a consequence of) that individual's values, instead of those values being derived from such susceptibility. We will thus assume and hypothesize this causal sequence.

\section{DIFFERENT DIMENSIONS OF VALUES}

Although the relative importance of different values to an individual have frequently been measured using the method devel- oped by Rokeach (1973), a simplified alternative, the List of Values (LOV), has often been used in various contexts (Kahle, 1996; Kahle, Beatty, \& Homer, 1986) and is used here. The LOV consists of nine values - a sense of belonging, excitement, fun and enjoyment in life, warm relationships with others, self-fulfillment, being well-respected, a sense of accomplishment, security, and self-respect. Studies have shown that these nine values can usually be reduced to three dimensions through factor analyses. Homer and Kahle (1988) found, in their factor analysis, an External Values dimension in which sense of belonging, being well-respected, security, and warm relationships with others had the four highest loadings. A second dimension was called Internal Values, with high loadings for self-fulfillment, sense of accomplishment, and self-respect, all of which are less dependent on others (excitement also had a high loading on this factor). The third dimension loaded strongest on fun and enjoyment, with excitement values loading somewhat lower (and having high loadings also for warm relationships with others); this Fun/Excitement Values factor is discussed further later. The rationale for labeling the first two dimensions external and internal is that external values should depend on others for fulfillment, whereas individuals can fulfill their internal values by themselves. Note that such labeling is used merely to communicate this important "depend on others versus depend on oneself" difference between these two factors; it should not be taken literally to mean that no other factors exist or that they are mutually exclusive. It could be argued, for instance, that security is conceptually an internal value as much as an external one, because it can for some people refer not only to being safe from external threats, but also to a person's desire for stability in his or her own world and a "peace of mind" preference for the familiar (known) over the unfamiliar (unknown), which are both arguably more internal than external.

Kamakura and Novak (1992) recently used a new latent measurement model on LOV data to develop four latent value-system segments and a "values map" showing the underlying dimensions of these segments. Consistent with the structure of human values suggested by Schwartz and Bilsky (1987), they found three underlying values dimensions in their values map, which they called Hedonism, Empathy, and Achievement. Their hedonism dimension has high weights on the LOV values of fun and enjoyment and excitement, similar to the fun/excitement factor referred to previously. Their empathy dimension has high weights on the LOV values of warm relationships with others and a sense of belonging, not dissimilar to the external values factor discussed previously. Their achievement dimension had its highest weights on sense of accomplishment, self-respect, and self-fulfillment, very similar to the internal values factor. Thus, their interpretation of the underlying dimensionality of $L O V$ values is very similar to the internal values, external values, and fun/excitement factor structure found by others (e.g., Homer \& Kahle, 1988).

Because the motivational underpinnings of SNI are the desires to identify and comply with the norms of reference 
groups (cf. Burnkrant \& Cosineau, 1975; Kelman, 1961), it should relate most strongly to those values that lead to a greater desire to be obedient to, and comply with, others-such as being well-respected, sense of belonging, and warm relationships with others, our external values. In contrast, we should expect no such relation between SNI and the internal values of self-fulfillment, self-respect, and so forth, which stress "self-direction" (cf. Schwartz, 1992).

It is less clear, however, what relation to SNI we should expect for the fun/excitement factor. In some prior research, there is evidence that fun and enjoyment in life and warm relationships with others can load on the same factor (Homer \& Kahle, 1988; Kamakura \& Novak, 1992; Kennedy, Best, \& Kahle, 1988). Because warm relationships with others is clearly an externally oriented value, these results would suggest that the fun/excitement factor ought to behave in a way similar to other external values. On the other hand, Schwartz (1992) argued that Stimulation Values (including an exciting life) arises from needs "related to the needs underlying self-direction values" such as self-respect and "choosing own goals," implying that they have an internal origin. Thus, in his scheme (but in our terminology), fun/excitement values ought to behave in an internal, not external, manner. Supporting this view, Herche (1994) reported an analysis in which excitement and fun/enjoyment relate most strongly to self-fulfillment, one of our internal values, and in Homer and Kahle's (1988) results, excitement also loaded highly on the internal values factor.

In summary, although external values ought in general to influence SNI, and internal values should not, opposing and situation-contingent predictions can be made about how our fun/excitement factor ought to relate to SNI. Kahle (1983), in a direct test of the relation between the LOV and locus of control, found that although external and internal values differed from each other significantly on this scale, the fun values fell in the middle of the range on this measure and did not differ significantly from either the internal or external values. Thus, fun and excitement gratification could appear to result either from self-activities (such as going down a water slide) or activities of others (as in a team sport), rendering their status on this dimension mid-range and situational. It is possible that, because the domain of interest in our study pertains to socially visible consumption, the salience of these external methods of value gratification might increase in our data, such that our fun/excitement values factor might function in a manner consistent with our expectations for the external values factor in terms of its relations with SNI. However, because of the situational uncertainty just mentioned, we will not offer this position as a formal hypothesis, although we will estimate these relations and comment on them.

\section{IMPORTANCE WEIGHTS ON ATTRIBUTES}

Consumer research on values has long posited a flow from values to product attribute or benefit weights (e.g.,
Reynolds \& Gutman, 1988, whose "means-ends" analysis argued that consumers prefer specific attributes because of the desired consumer end-values that those attributes, the means, help achieve). Such relations are almost definitional: If values are defined as preferred end-states of existence (cf. Rokeach, 1973), then these differential attribute importance weights - -stating which attributes of products are more preferred-should logically be related to values. Attribute importance weights can be seen as concrete manifestations, or "operationalizations," in specific category situations, of this more abstract or "latent" value preference. Some prior empirical research has already shown a relation between values and attribute weights in different product categories, such as automobiles and clothing (see, e.g., Vinson, Scott, \& Lamont, 1977).

Furthermore, the literature on intentions-formation has also previously suggested that a concern with social consequences should lead to a higher evaluation of attributes that are socially more important. Miniard and Cohen (1979) suggested that "social reasons for buying a particular product are typically reflected in one's evaluation of ... product attributes (e.g., white teeth and fresh breath in toothpaste, 'style' in clothing" (p. 103). Thus, consumers with a high concern with normative influences (high SNI) ought to place greater evaluation (higher weight) on such "socially visible" attributes than consumers with low SNI, because the social benefits of such socially visible attributes ought to matter more to consumers concerned with social approval.

Because we have argued earlier that values (especially external values) are causally prior to SNI, it logically follows that the effect of values on attribute importance weights should be mediated, at least partly, by SNI. In other words, if consumers have high SNI because of the antecedent effect (in the trait hierarchical sense used by Joachimsthaler \& Lastovicka, 1984) of the greater importance they place on external values, and if high SNI leads to a higher concern with social consequences such that higher importance weights are placed on socially visible attributes, then the relation between external values and attribute weights ought to be mediated by SNI. It seems theoretically implausible, given the hierarchical relations we have laid out, that the effect of external values on attribute importance weights is totally direct, without going at least partly through SNI. Indeed, if SNI turns out to totally mediate the effect of external values on attribute importance weights, then marketing studies need only use SNI as the relevant segmentation variable and could ignore the hierarchically antecedent construct of external values, because SNI would capture their effect on attribute importance weights.

\section{SUMMARY AND HYPOTHESES}

To summarize, then, our theoretical development suggests the following nomological network, indicating partial or complete mediation by SNI of the effect of external values (such as being well-respected, warm relationships, and sense of be- 
longing) in raising attribute importance weight for attributes that provide socially visible benefits (such as a product's externally visible styling):

\section{External values $\rightarrow \mathrm{SNI} \rightarrow$ attribute importance weights}

The hypotheses discussed later reflect this nomological network. We first hypothesize $(\mathrm{Hl})$ that the relation between values and SNI is significant only for the external values dimension, which measures the importance to the individual of values such as belonging, being well-respected, and warm relationships. In contrast, we expect no such significant relation for internal values (and explore the relation with fun/excitement values.) Second, we hypothesize (H2) a significant relation between SNI and attribute importance weight for attributes that lead to socially visible benefits, but no such significant relation between SNI and those attributes that lead to benefits that are not socially visible. Third, we hypothesize (H3) that SNI should mediate, either partially or completely, the effects of external values on socially visible attribute importance weights.

\section{METHOD}

The data used here come from a national field survey of a mail panel conducted as part of a larger research project. The 1,000 people to whom the survey was mailed were selected to be nationally representative (i.e., matched to census proportions) on age (between ages 18-70), sex, education, and income. The overall response rate was $66.3 \%$ (varying only slightly across demographic subgroups) and led to a sample size of 663. Such a high response rate usually reduces nonresponse biases, and we obtained a very wide and nationally representative distribution on gender, income, race, education, and age (details omitted for brevity). Among hundreds of other items, these panelists answered questions in this sequence: some SNI items, generic attribute weights, some more SNI items, clothing attribute importance weights, values, the remaining SNI items, and the demographic items. The nondemographic questions were distributed across different batteries of items, which appeared separately and used different types of scales (e.g., some were agree-disagree scales, and others were Likert scales), so as to reduce respondent fatigue. Although the questionnaire did not use standard scales for SNI, three sets of measures in this data set appeared to possess enough content and measurement adequacy to allow the testing of relations between values, SNI, and attribute importance weights and were therefore used to test our hypotheses.

\section{Measures}

Values. To measure values, respondents were asked to provide importance ratings on 7-point scales, from 1 (extremely important) to 7 (not at all important), of various value items, in- cluding the nine LOV items analyzed here (self-respect, security, warm relationships with others, self-fulfillment, sense of accomplishment, being well-respected, sense of belonging, excitement, and fun and enjoyment in life).

The adequacy of the three-factor measurement structure discussed previously (external, internal, and fun/excitement factors) was examined as part of a comprehensive measurement model test using LISREL 8.30 (Jöreskog \& Sörbom, 1993), reported later. Before that comprehensive measurement test was performed, however, other preliminary LISREL measurement models on just the values data confirmed that a three-factor solution provided a superior fit to the data compared to a single factor solution. Specifically, the three-factor model had a significantly lower chi-square and significantly higher fit statistics (higher adjusted goodness-of-fit index, or AGFI, and normed fit index, or NFI, and lower root mean square error of approximation, or RMSEA) than a one-factor model or two-factor models. In addition, the model fit better if security-which, as discussed, could theoretically be claimed to be internal as well as external-was dropped. Thus, these three factor constructs, with security deleted, were modeled in that comprehensive measurement model reported later.

SNI. Seven items were used in the survey to measure the individual's SNI. Because when the survey schedule was developed we did not have access to the Bearden et al. (1989) scales, the survey items used were very similar, but not identical, to those identified by Bearden et al. as validly measuring SNI. (See Table 1.) One difference is that although our survey items referred to the influence of "friends," Bearden et al.'s SNI items referred to the influence of "others." Because the most relevant reference group for most social choices is likely to be friends one associates with (rather than teachers or civic leaders), this deviation is not unreasonable. Because of these and other wording differences, however, data from two follow-up studies were subsequently used to establish that the two sets of scales measured the same SNI domain and to identify the "most valid" items from our survey.

To analyze which of our 7 survey items were most closely measuring the same domain measured by the 8 Bearden et al. (1989) items, all 15 items were administered to participants in two separate follow-up studies. Because the mail panel used in the main study was no longer available to us, these follow-up studies were conducted among university undergraduates. In each instance, the administered battery of 15 items used alternated the 8 Bearden et al. items with our 7 . Confirmatory factor analysis (via LISREL) was then applied to each of these two data sets to compare a two-factor measurement model (with factor one being Bearden et al.'s items and factor two being our items) versus a one-factor model (using all items). If the two-factor structure fit better, this result would suggest that the two sets of items were measuring different domains, although support for a one-factor structure would argue for the two sets measuring the same (SNI) domain. The results of these analy- 
TABLE 1

Measurement of Susceptibility to Normative Influence

A. Items used in our main study to measure Susceptibility to Normative Influence

1. Features/Qualities important to me when I shop are ... (7-point importance ratings, extremely important to not at all important):

a. Friends must like it

b. Friends also have it

2. How much do you like the following? (7-point rating, like extremely well to do not like at all):

Buying the same brands/products your friends do

3. How strongly do you agree or disagree with the following statements? (7-point rating scales, strongly agree to strongly disagree)

a. My friends and I tend to buy the same brands.

b. I buy brands which will make me look good in front of my friends.

c. It is important to have a lot of friends with whom I can do things.

d. When I buy the same things my friends buy, I feel closer to them.

B. Items used by Bearden et al. (1989) for Susceptibility to Normative Influence

1. When buying products, I generally purchase those brands that I think others will approve of.

2. If other people can see me using a product, I often purchase the brand they expect me to buy.

3. I achieve a sense of belonging by purchasing the same product and brands that others purchase.

4. I often identify with other people by purchasing the same products and brands they purchase.

5. If I want to be like someone, I often try to buy the same brands that they buy.

6. I like to know what brands and products make good impressions on others.

7. I rarely purchase the latest fashion styles until I am sure my friends approve of them.

8. It is important that others like the products and brands I buy.

ses (not reported here for brevity, but available in a longer version of this article) identified four items in our data that (a) demonstrated a one-factor structure with the Bearden et al. items and (b) achieved a composite construct reliability (CCR; cf. Werts, Linn, \& Jöreskog, 1974) of 0.73 and an average variance extracted (AVE; cf. Fornell \& Larcker, 1981) statistic of 0.45 . Although these indexes are lower than what we would like (in part because our items came from widely dispersed and differently worded question batteries in our survey), they are the best achievable in these field survey data if four or more items are to be used. Reducing these four SNI items to just the best two items would have improved their measurement properties (CCR up to 0.88 , AVE up to 0.78 ), but would imply measuring the crucial SNI construct with just two items, which would arguably be too drastic a reduction and could lead to "capitalizing on chance." We therefore chose to continue working with the four best SNI items in our data. Model estimation with just the two best items yielded virtually identical results.

Attribute importance. The mail field survey also collected data to measure the importance placed on different attributes. These data were collected for two different product category domains (described below). In each of these two domains, respondents rated the importance of various attributes in selecting a brand in that category on a 7-point scale from 1 (not at all important) to 7 (extremely important).

The first set of attribute importance ratings covered clothing and was based on the list developed, through focus groups, by Prakash (1984). Eleven attributes were used, and exploratory factor analysis yielded four dimensions, with these highly loading items: reputation (manufacturer or brand repu- tation; made by famous designer), style (currently in fashion, style, will not go out of fashion soon), fit (quality fabric, value for money, fit, comfort), and care (ease of care, durability).

For greater generality, the second data set of attribute importance ratings used 14 generic product attributes, which should be applicable across all relevant product categories, modified from the consumption-domain list offered by Vinson, Scott, and Lamont (1977). These 14 generic attributes were durable and long lasting; reasonably priced; safe; inexpensive to use; easy to use or maintain; exciting and stylish; dependable, trustworthy; beautiful and attractive; easy to repair or fix; comfortable, secure; made by well-known company; fits my own tastes exactly; cheapest available; and quality. Exploratory factor analysis reduced these to seven dimensions, with these highly loading items: easycare (easy to use, easy to repair), durability (durable, dependable, safe, comfortable or secure), attractiveness (exciting, attractive), price (reasonably priced, cheapest available, inexpensive to use), tastes (fits my own tastes exactly), quality (quality), and company (made by well-known company).

For both data sets individually, preliminary confirmatory factor analyses were used to assess the validity of these dimensions and to improve their measurement properties through deletion of poorly fitting items. Our final, comprehensive measurement model estimates of their convergent and discriminant validity are discussed later.

\section{Social Visibility of These Attributes}

To determine the extent to which the specific attributes used in the importance ratings were socially conspicuous, a differ- 
ent set of subjects were used - as part of the first follow-up SNI measurement study - to rate whether each attribute was one offering "private" benefits ("benefits which only the user himself or herself will know about") or socially visible benefits (those benefits that would be "visible not only to the user, but also to friends, etc.'), using a 7-point private to socially visible scale.

When the individual clothing attributes were subsequently rated by this different respondent sample ( $n=107$ students) on offering private or socially visible benefits, the reputation scale (created by averaging the items in that factor) was rated high on social visibility $(M=5.78)$, with 1 (private) and 7 (socially visible), as was the style multi-item scale $(M=5.39)$. In contrast, the fit and care multi-item scales were each rated between 2.26 (for care) to 3.10 (for fit). Pairwise comparisons of the means of these scales (using tests for paired samples) showed that the reputation and style means were each significantly much greater than the means of the fit and care scales (each pairwise $t>14, p<.001$ ). Thus, the reputation and style attributes in clothing offer relatively more socially visible benefits than fit and care benefits.

When the individual generic attributes were subsequently rated by this respondent sample on offering private versus socially visible benefits, the attractiveness scale was rated high on social visibility $(M=5.71)$, as was the company scale (5.73). The quality scale was midrated at 3.97. The remaining easycare, durability, price, and tastes scales were each rated between 2.21 (for tastes) to 2.92 (for durability). Pairwise $t$ tests showed that the attractiveness and company scales measure relatively more socially visible benefits, although the easycare, durability, price, and tastes benefits are relatively more private (and quality is in-between).

\section{Comprehensive Measurement Model Test}

In keeping with the procedure recommended by Anderson and Gerbing (1988), a comprehensive measurement model was estimated that included all constructs and measures subsequently used in the testing of structural relations, through a confirmatory factor analysis using LISREL. Following tradition, the scale of measurement for the constructs was established by fixing one of the factor loadings to 1.0. For those single-item constructs where multiple indicators were not available (i.e., quality, tastes, and company), the measurement errors were fixed at $(1-\alpha)$ times the variance of the indicator, rather than zero; this approach is a standard but conservative procedure. A reliability of 0.85 was assumed here (cf. MacKenzie \& Lutz, 1989). The overall goodness-of-fit statistics for this comprehensive measurement model were acceptable: $\chi^{2}(362, N=663)=1071.23, p<.001$; goodness-of-fit index $(\mathrm{GFI})=.91, \mathrm{AGFI}=.87$, Bollen's (1989) Incremental Fit Index $(\mathrm{IFI})=.92$. (Note that the large survey sample size of 663 leads to the high chi-square and low $p$ values of these models, Long, 1983, making them a poor gauge of overall model fit. An IFI of 0.90 or better is considered good fit.).

Ten of the twelve constructs used each had AVEs equaling or exceeding 0.50 , indicating acceptable convergent validity. One exception was the four-item SNI construct, which fell slightly below this conventional benchmark $(C C R=0.73$, $\mathrm{AVE}=0.45$ ). As discussed earlier, using a two-best-item SNI scale would have raised the CCR to 0.88 and the AVE to 0.78 , but we chose not to use just the two strongest items from these four because we judged it important that this core construct not be based on just two items, and reestimating our final structural models using just the two-best SNI items did not change any of our results. The other exception to a satisfactory AVE and CCR was the generic attribute of price $(\mathrm{CCR}=$ $0.61, \mathrm{AVE}=0.44$ ).

Discriminant validity among these latent constructs was first tested by seeing if their pairwise correlations (adjusted for measurement error) were each significantly different from 1.0, a standard test (Anderson \& Gerbing, 1988). None of these correlations were greater than 0.80 , and all were more than three standard errors away from 1.0 , indicating that they were all significantly different from 1.0 at $p$ $<.01$. A stricter test of discriminant validity among each pair of constructs is to see if the variance extracted estimates for each construct exceed the square of the interconstruct correlations for that pair (Fomell \& Larcker, 1981). This stricter test too was met for all pairings of the key constructs (external values, internal values, fun values, and SNI). Three of the eleven attributes failed to meet this stricter test when paired (easycare, durability, price), but because their intercorrelations (at .80 or below) all met the weaker test, and because reducing their measures to fewer items would do more harm than good (they already had two or fewer items), no changes were made in their measures.

\section{RESULTS}

The three hypotheses were tested through confirmatory factor analysis (LISREL) estimates, by specifying a recursive model (see Figure 1) in which the three values constructs influenced SNI, which then influenced the attribute importance constructs. In addition, respondent age (which was also available in the data) was used as a covariate: Its use is important because it helps remove the confounding effects that would arise if significantly related variables are omitted from models of SNI relations (Bearden \& Etzel, 1982). Age was previously shown to affect values (Crosby, Gill, \& Lee, 1984), SNI (Park \& Lessig, 1977), and attribute importance weights (Goodhead, 1991), although these effects of age on SNI and on attribute weights do not occur only and completely through values (Valette-Florence \& Jolibert, 1990). We thus modeled covariate links from age to the values constructs, to SNI, and to the attribute importance weights. The two other available demographic variables (income and education) were unrelated 
to SNI in these data and were therefore not modeled. The correlations among the three values constructs and among the (clothing or generic) attribute importance constructs were also estimated in these models (for brevity, these intercorrelations-all significant at $p<.05$ - are omitted from the results that follow). Although zero-order correlations among the key constructs varied slightly across the clothing and generic data sets, they were about 0.29 between external values and SNI, and 0.17 between internal values and SNI. The correlations between external values and the attribute weights ranged from 0.05 to 0.50 , were slightly higher for external values than for internal values, and were higher for the style and reputation attributes in clothing and the attractiveness and company attributes for the generic data. SNI also correlated most highly with these same attribute weights, with the correlations between 0.3 and 0.5 . Similar to the comprehensive measurement model test reported previously, the measurementerror for each of the single-indicator constructs was fixed at $(1-\alpha)$ times the variance of the indicator, assuming a reliability of 0.85 .

Recall that, according to our hypotheses, the effects of values on SNI are significant only for external values $(\mathrm{H} 1)$; the effects of SNI on attribute importance weights are significant only for socially visible attributes (H2); and SNI mediates, partially or completely, the significant effects of the external value dimensions on the socially visible attribute importance weights (H3). The significance or nonsignificance of the hypothesized paths ( $\mathrm{H} 1$ and $\mathrm{H} 2)$ can be tested directly through the LISREL estimates. The hypothesized mediation by SNI (H3) then obviously applies only to those value attribute im- portance relations that prove significant in the tests discussed previously, and for which a relation can be shown between values and the attribute importance rating before SNI is introduced as a potential mediator. Here, because the estimated model specifies both the direct paths between the values constructs to each attribute importance construct, as well as the indirect paths to and from SNI, mediation (H3) is indicated if the indirect paths from each value to each attribute importance weight, via SNI, are significant, in a model in which SNI is tested as a potential mediator of the value attribute importance relation. Full mediation is indicated if these indirect paths are significant but the direct paths are not significant, although partial mediation is indicated if both the indirect and direct paths are significant.

\section{Clothing Attributes}

A causal model estimating "all paths" had the following fit statistics: overall $\chi^{2}(174, N=663)=555.43, p=.000, \mathrm{GFI}=$ .93 , $\mathrm{AGFI}=.90$, root mean square residual $(\mathrm{RMR})=0.108$, RMSEA $=0.0578, p$ value for close fit $=0.009$. When this chi-square is compared to that of the null model of modified independence, as suggested by Bollen (1989), the IFI is 0.93 , above the conventional cutoff of 0.90 . Note that the chi-square is high and the $p$ statistic low because of the high sample size $(N=663)$.

The standardized path coefficients of the all paths model in Table 2 (Column 1) show that, as hypothesized (H1), the path between external values and SNI was significant $(.25, p<$

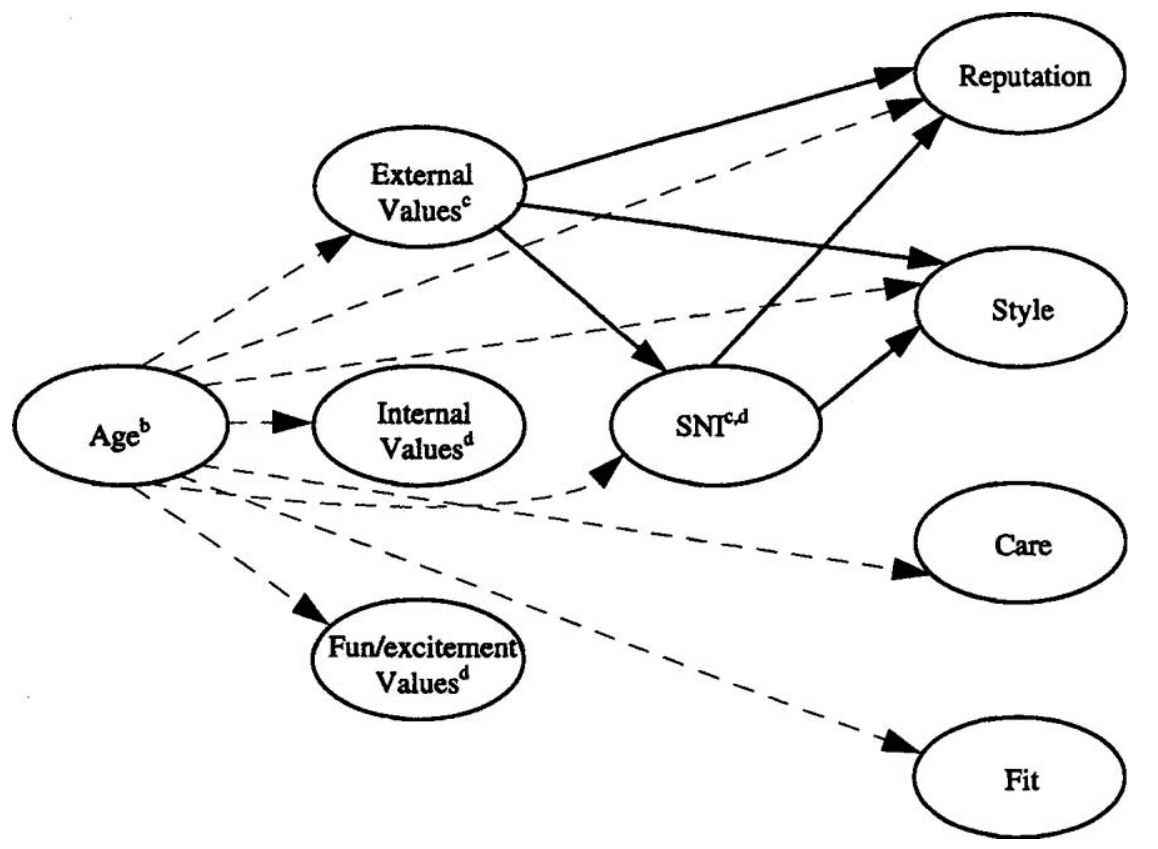

FIGURE 1 Schematic of hypothesized structural model (clothing data). aIntercorrelations among values and attribute importance weights omitted for simplicity. ${ }^{\text {broken-line paths from age depict covariate relations. }}$ "All straight-line paths from External Values, and from SNI, depict hypothesized relations. dNonhypothesized paths from Internal Values and Fun/excitement Values, and from SNI to Care and Fit, are not shown here for simplicity but were estimated (see Tables). 
TABLE 2

Summary of Standardized Structural Estimates for Clothing Attributes Models

\begin{tabular}{lcc}
\hline & \multicolumn{2}{c}{ Standardized Path Coefficients } \\
\cline { 2 - 3 } Estimated Path & All Paths Model & $\begin{array}{c}\text { Hypothesized } \\
\text { Paths Model }\end{array}$ \\
\hline Age $\rightarrow$ external values & $.132^{* *}$ & $.132^{* *}$ \\
Age $\rightarrow$ internal values & .031 & .031 \\
Age $\rightarrow$ fun values & $-.148^{* *}$ & $-.147^{* *}$ \\
Age $\rightarrow$ SNI & $.103^{* *}$ & .060 \\
Age $\rightarrow$ reputation & -.009 & -.048 \\
Age $\rightarrow$ style & .003 & -.017 \\
Age $\rightarrow$ care & $.181^{* *}$ & $.176^{* *}$ \\
Age $\rightarrow$ fit & $.101^{* *}$ & $.127^{* *}$ \\
External values $\rightarrow$ SNI & $.245^{* *}$ & $.291^{* *}$ \\
Internal values $\rightarrow$ SNI & $-.146^{*}$ & \\
Fun values $\rightarrow$ SNI & $.217^{* *}$ & $.482^{* *}$ \\
SNI $\rightarrow$ reputation & $.476^{* *}$ & $.241^{* *}$ \\
SNI $\rightarrow$ style & $.239^{* *}$ & \\
SNI $\rightarrow$ care & -.069 & $.100^{* *}$ \\
SNI $\rightarrow$ fit & $-.116^{* *}$ & $.257^{* *}$ \\
External values $\rightarrow$ reputation & -.071 & \\
External values $\rightarrow$ style & $.156^{*}$ & \\
External values $\rightarrow$ care & $.170^{*}$ & \\
External values $\rightarrow$ fit & $.264^{* *}$ & \\
Internal values $\rightarrow$ reputation & .100 & \\
Internal values $\rightarrow$ style & .099 & \\
Internal values $\rightarrow$ care & .091 & \\
Internal values $\rightarrow$ fit & .074 & \\
Fun values $\rightarrow$ reputation & .132 & \\
Fun values $\rightarrow$ style & .068 & \\
Fun values $\rightarrow$ care & $.152^{*}$ & \\
Fun values $\rightarrow$ fit & -.003 & \\
\hline$\quad$ a & & \\
\hline & &
\end{tabular}

Note. $\mathrm{SNI}=$ susceptibility to normative influence.

${ }^{*} p<.10 .{ }^{* *} p<.05$.

$.05)$. The path between fun/excitement values and SNI was also significant $(.22, p<.05)$. This positive and significant relation between fun/excitement values and SNI suggests that this third values dimension too might be external in our data, a possibility raised in our discussion section.

Also as hypothesized (H2), the paths between SNI and the attribute importance weights were significant in a positive direction only for the two socially visible attributes (i.e., for reputation $.48, p<.05$; and style $.24, p<.05$ ). The relation is not significant for care $(-.07, n s)$ and is actually significant in a negative direction for the fit scale $(-.12, p<.05)$. (Note that this fit scale consists of the four items fit, comfort, value for money, and quality fabric).

We turn now to the hypothesized mediation by SNI of the significant relations between external or fun/excitement values, and the importance weights of the two socially visible attributes of reputation and style (H3). The LISREL comprehensive measurement model showed earlier that the correlations between each of these four pairs of latent constructs (corrected for measurement error) were strong and significant, indicating significant relations between each specific value and specific attribute weight. In addition, a multivariate analysis of variance (MANOVA) performed on median split of the sample, on the SNI scale, also showed that high SNI participants were placing higher weights on reputation (high $\mathrm{SNI}=5.21$, low $\mathrm{SNI}=4.18, p<.001$ ), style (high $\mathrm{SNI}=3.73$, low $\mathrm{SNI}=3.00, p<.001$ ), and fit (high SNI $=1.38$, low $\mathrm{SNI}=1.22, p<.001$ ). The results of the Table 2 estimates (Column 1) now show that in each of these four cases the direct paths (between external and fun values, and reputation or style) were not significant at $p<$ .05 . Because the direct paths were not significant at $p<.05$, although the indirect paths (through SNI) were (see earlier results), SNI appears to fully mediate these relations, supporting the hypothesis.

Another model, with just the hypothesized paths, was also estimated, and its results appear in Column 2 of Table 3. Although this "hypothesized paths only" model has fit statistics slightly below those of the all paths model, $\chi^{2}(188, N=663)=648.58, p=.000, \mathrm{GFI}=.92, \mathrm{AGFI}=$ $.89, \mathrm{RMR}=0.133, \mathrm{RMSEA}=0.0609, p$ value for close fit $<$ .001 , calculations showed that it has a "parsimonious normed fit index" (PNFI; cf. Mulaik et al., 1989) of 0.72, higher than one for the all paths model of 0.68 , indicating that the hypothesized paths model is superior if one considers not only model fit but also model parsimony. (The PNFI multiplies the NFI by the ratio of the degrees of freedom $\left(d_{j}\right)$ of the model divided by the degrees of freedom $\left(d_{o}\right)$ of the null model. This reduction in value of the NFI compensates for the increase in fit of a less restricted model obtained at the expense of degrees of freedom lost in the estimation of free parameters, according to Mulaik et al. (1989). These hypothesized model results are very similar to the results from the all paths model just discussed. The path between external values and SNI is again significant, and the paths between SNI and the attribute importance weights are significant in a positive direction for the two socially visible attributes (reputation and style); however, these Column 2 results suggest only partial mediation by SNI, because the direct paths from external values to reputation and to style are both significant at $p<.05$.

\section{Generic Attributes}

The all paths model for generic attributes (see Column 1 of Table 3) fits about as well as the equivalent clothing attributes model, $\chi^{2}(190, N=663)=657.66, p=.000, \mathrm{GFI}=.93, \mathrm{AGFI}$ $=.88, \mathrm{RMR}=0.0873, \mathrm{RMSEA}=0.0603, p$ value for close fit $<.001$, Bollen's IFI $=.92$. Results from the hypothesized paths only model are in Column 2. This latter model has a $\chi^{2}(216, N=663)=835.25, p=.000, \mathrm{GFI}=.91, \mathrm{AGFI}=.87$, $\mathrm{RMR}=0.144, \mathrm{RMSEA}=0.0641, p$ value for close fit $<.001$, Bollen's IFI $=.89$, and again has a higher PNFI than the all paths model, of 0.67 versus 0.61 . The standardized coefficients for the paths between the three values and SNI in the all paths model were about the same as in the clothing model, be- 
TABLE 3

Summary of Standardized Structural Estimates for Generic Attributes Models

\begin{tabular}{|c|c|c|}
\hline \multirow[b]{2}{*}{ Estimated Path } & \multicolumn{2}{|c|}{ Standardized Path Coefficients } \\
\hline & All Paths Model & Hypothesized Paths Model \\
\hline Age $\rightarrow$ external values & $.132^{* *}$ & $.132^{* *}$ \\
\hline Age $\rightarrow$ internal values & .032 & .031 \\
\hline Age $\rightarrow$ fun values & $-.150 * *$ & $-.148 * *$ \\
\hline Age $\rightarrow$ SNI & $.105 * *$ & .060 \\
\hline Age $\rightarrow$ easy care & $.153^{* *}$ & $.210^{* *}$ \\
\hline Age $\rightarrow$ durability & $.095^{*}$ & $.109 * *$ \\
\hline Age $\rightarrow$ attractive & .029 & -.004 \\
\hline Age $\rightarrow$ price & -.008 & .052 \\
\hline Age $\rightarrow$ tastes & $.116^{* *}$ & $.162 * *$ \\
\hline Age $\rightarrow$ quality & $.108 * *$ & $.121^{* *}$ \\
\hline Age $\rightarrow$ company & $.151^{* *}$ & $.118^{* *}$ \\
\hline External values $\rightarrow$ SNI & $.244^{* *}$ & $.291^{* *}$ \\
\hline Internal values $\rightarrow$ SNI & $-.154 *$ & \\
\hline Fun values $\rightarrow$ SNI & $.228 * *$ & \\
\hline SNI $\rightarrow$ easy care & -.023 & \\
\hline $\mathrm{SNI} \rightarrow$ durability & -.052 & \\
\hline SNI $\rightarrow$ attractive & $.457^{* *}$ & $.475^{* *}$ \\
\hline $\mathrm{SNI} \rightarrow$ price & $.147^{* *}$ & \\
\hline $\mathrm{SNI} \rightarrow$ tastes & .077 & \\
\hline SNI $\rightarrow$ quality & -.025 & \\
\hline $\mathrm{SNI} \rightarrow$ company & $.395^{* *}$ & $.405^{* *}$ \\
\hline External values $\rightarrow$ easy care & $.399 * *$ & \\
\hline External values $\rightarrow$ durability & .101 & \\
\hline External values $\rightarrow$ attractive & .055 & $.136^{* *}$ \\
\hline External values $\rightarrow$ price & $.259^{* *}$ & \\
\hline External values $\rightarrow$ tastes & .098 & \\
\hline External values $\rightarrow$ quality & .048 & \\
\hline External values $\rightarrow$ company & -.016 & $.114^{* *}$ \\
\hline Intemal values $\rightarrow$ easy care & .100 & \\
\hline Internal values $\rightarrow$ durability & $.253^{* *}$ & \\
\hline Internal values $\rightarrow$ attractive & .047 & \\
\hline Internal values $\rightarrow$ price & .107 & \\
\hline Internal values $\rightarrow$ tastes & $.329 * *$ & \\
\hline Internal values $\rightarrow$ quality & $.285^{* *}$ & \\
\hline Internal values $\rightarrow$ company & .111 & \\
\hline Fun values $\rightarrow$ easy care & -.019 & \\
\hline Fun values $\rightarrow$ durability & -.013 & \\
\hline Fun values $\rightarrow$ attractive & $.195 * *$ & \\
\hline Fun values $\rightarrow$ price & -.054 & \\
\hline Fun values $\rightarrow$ tastes & -.100 & \\
\hline Fun values $\rightarrow$ quality & -.006 & \\
\hline Fun values $\rightarrow$ company & $.136^{*}$ & \\
\hline
\end{tabular}

Note. $\mathrm{SNI}=$ susceptibility to normative influence.

${ }^{*} p<.10 .{ }^{* *} p<.05$.

cause this portion of the data covariance matrix was identical in both cases. Thus, supporting $\mathrm{Hl}$, the relation between external values and SNI was significant and positive $(.24, p<$ .05 ; it is also significant in the Column 2 of hypothesized paths only results). As in the clothing model, the relation between fun/excitement values and SNI was also significantly positive $(.23, p<.05)$.

Supporting H2, the paths between SNI and the attribute importance weights in the all paths model were significant for the socially visible attributes of attractiveness $(.46, p<.01)$ and company $(.40, p<.05)$. (These results appear in the Column 2 model as well.) As expected, paths are nonsignificant at $p<.05$ between SNI and the nonsocial attributes of easycare $(-.02, n s)$, durability $(-.05, n s)$, tastes $(.08, n s)$, and quality $(-.03, n s)$. However, the path from SNI also unexpectedly turned out to be significant for the attribute of price $(.15, p<.05)$, a result discussed later.

We turn now to the hypothesized mediation by SNI of the significant relations between external or fun/excitement values, and the importance weights of the two socially visible at- 
tributes of attractiveness and company (H3). The LISREL measurement model (reported earlier) had shown that the correlations between each of these four pairs of latent constructs (corrected for measurement error) were strong and significant, indicating that a relation between that specific value and that specific attribute weight clearly exists in each case. A MANOVA using a median split of the sample, on the SNI scale, also showed that high SNI participants were placing higher weights on attractiveness (high $\mathrm{SNI}=4.00$, low $\mathrm{SNI}=$ $2.97, p<.001$ ) and company (high $\mathrm{SNI}=3.79$, low $\mathrm{SNI}=$ $2.68, p<.001$ ). The all paths results in Table 3 (Column 1) now showed that in the case of external values to attractiveness, external values to company, and fun/excitement to company, the direct paths were not significant at $p<.05$, although the indirect paths via SNI were significant (as discussed earlier), indicating full mediation by SNI. (As in the clothing data, the Column 2 hypothesized model results only support partial mediation here by SNI, for they show these direct paths between external values and attribute weights to still be significant.) For the remaining path, that of fun/excitement to attractiveness, SNI proves to be a partial mediator, because of a significant direct effect in Column $1(.20, p<.05)$. As for the unexpected relations between external or fun/excitement values and price, SNI appears to mediate this relation fully for fun/excitement values (no direct effect in Column 1 at $p<.05$ ) and partially for external values (significant direct effect $=$ $.26, p<.05)$.

\section{DISCUSSION}

Our results, using a large and nationally representative data set, mostly support key portions of the nomological network for SNI suggested in our theoretical review. They show first that although external and fun/enjoyment values each have a significant positive relation with SNI, internal values do not. Second, the effect of SNI itself on attribute importance weights is stronger for those attributes where a socially visible benefit can be inferred than for those attributes where such a benefit is apparently lacking. For clothing, these socially visible attributes were reputation and style; and for generic attributes they were attractiveness, company, and (surprisingly) price. Finally, the effect of these values on the attribute importance weights apparently occurs both indirectly (mediated by SNI) and directly, depending on the specific attribute domain. In the all paths models, SNI fully mediates the hypothesized values-to-attribute-weight relations for clothing and for generic attributes.

In spite of the few unexpected findings, our results make an important contribution to the literature on reference group influences by placing SNI in a wider theoretical network. Bearden et al. (1989) already showed that SNI relates in hypothesized ways to self-esteem and to actual concern with the approval of others. By providing empirical support for the first time for intuitive relations between SNI and two constructs important in understanding consumer behavior-social values and attribute importance weights-our results add significantly to the nomological network (Cronbach \& Meehl, 1955) around this new and important SNI construct. By suggesting that the motivational underpinnings of SNI are the desires to identify and comply with the norms of reference groups (cf. Burnkrant \& Cosineau, 1975; Kelman, 1961), which have their antecedents in the external values of wanting to be well-respected and feeling a sense of belonging with others, our results provide further insight into the nature of SNI. In addition, our data also afford another demonstration of the primacy of the values construct and the antecedence of values to predispositions such as SNI. Our findings should especially encourage the use of SNI in future research into reference group influences on consumption decisions, which seem to be increasingly important in developed societies.

One of the surprising findings was that fun/excitement values behaved similarly in our data to those values clearly identifiable as external (such as being well-respected). This result is consistent with the evidence from some previous research (Homer \& Kahle, 1988; Kamakura \& Novak, 1992; Kennedy et al., 1988) that fun and enjoyment and excitement share some of the same motivations as warm relationships with others - an external orientation-at least in some domains. Our results in this regard, however, are not consistent with the values structure postulated by Schwartz (1992), whose theoretical clustering predicted that the fun values should cluster with the internal values, not the external values. Because the domain of interest in our study pertains to socially visible consumption, the salience of external methods of value gratification might have gone up in our data; this result may not happen in other situational contexts. It was suggested by one colleague that the external and fun/excitement values factors may be part of some higher order social factor. Tests of such a higher order model were not significantly better or worse than that of our original specification, suggesting the possibility that the two factors (external and fun/excitement) might indeed share a common motivational origin in our data. Further research is thus clearly indicated on how these two factors relate to each other in other contexts. If such future research also shows fun/excitement to behave similarly to our external values, it may suggest that the emotions of fun and excitement are usually experienced most fully (and valued more) in the presence of others, consistent with previous research that emotions and moods are contagious (Izard, 1977) and that the majority mood of a social group affects the moods of all its members (Schachter, 1971).

Also unexpectedly, although our pretest sample did not rate price (for generic attributes) as being socially visible, we did in fact find external values to lead to a higher weight for the price attribute. This result makes sense in hindsight, for the price of an article might serve a social signaling function; for example, the price of an expensive car purchased by a con- 
sumer represents not only an economic cost, but also serves as a signal to acquire prestige. It is not clear, however, why this relation was not perceived by our pretest participants; it might be that this discrepancy is due to measurement problems with our price construct, which showed evidence of unsatisfactory internal consistency, or it might have emerged because we were unfortunately only able to collect these ratings from students instead of our main sample of nonstudents.

\section{Limitations and Future Research}

Our model only explained a portion of the variance in our dependent variables. Age and the three values together explained $11 \%$ of variance in SNI; although age, the three values, and SNI together explained $8 \%$ to $35 \%$ of variance in the various attribute importance weights $(18-35 \%$ for the socially visible attributes) for clothing and generic attributes, respectively. Some of the unexplained variance may be due to the fact that our survey questions dealt with general purchase situations, not any one particular purchase context. It does, however, suggest the need to add other relevant variables to such models, which otherwise might have biased coefficient estimates. Estimates might also differ if the attributes used were different, and a more refined characterization of attribute differences might be helpful in future research (e.g., the search, experience, and credence attribute typology used by Ford, Smith, \& Swasy, 1990). Relatedly, more research is also required on the relation between SNI and other seemingly similar constructs, such as self-monitoring (Snyder, 1974) and the "agreeableness" factor often found in Big Five factors personality research (e.g., Digman \& Inouye, 1986).

The fact that our SNI measures are not identical to Bearden et al.'s (1989)-for example, by referencing friends instead of all others - are clearly a source of concern, although the structural equation estimates we obtained using LISREL are attenuated for measurement error. Also countering this measurement concern somewhat is the fact that our primary data come from a nationally projectible survey of "real people," not a convenience sample of university undergraduates. (Our follow-up measurement studies were unfortunately limited to a student sample, because we no longer had access to the national panel.) This aspect of our data adds value to the study, although the generic attribute importance weights we found and the nomological relations we obtained may not apply equally well to all product categories. Further work involving more product categories and using scales mentioning reference groups other than friends should add generalizability. Replication of this research within different content domains would also increase our confidence in the inferences. We believe that testing for additional dimensions of values could be useful because much evidence suggests that the clusters of values may be specific to content domains and cultures (Kahle, 1996). Further measurement work also ought to be done on our social visibility construct (e.g., by using "public-private" scales similar to those used by Bearden \& Etzel, 1982) and on eliminating the possibility that our measurement of this construct might somehow be confounded.

A major theoretical limitation of our results, bearing on the "internal validity" of our nomological network, is that our national field survey data are obviously correlational, not experimental. True causality can obviously not be conclusively tested in such data, even with confirmatory factor-analytic causal model path estimates such as those obtained here. Thus, such data are not capable of fully resolving issues of causal priority, and a preference for one causal ordering over another must be based on theoretical grounds (those presented earlier in our article). This study would therefore benefit from experimental follow-ups using manipulations of SNI, values, or both.

In spite of these limitations, which suggest avenues for future research, our results do succeed in throwing light on "the processes through which reference group influences operate and affect ... evaluation of alternatives ... (which) are in need of study" (Bearden \& Etzel, 1982, p. 192). These results potentially have implications not only for our understanding of brand and category choice, but also for why some teenagers begin consuming cigarettes and illegal drugs, and why some adults want to consume conspicuously or in ways that contribute to ecological and social problems.

\section{ACKNOWLEDGMENTS}

We thank Steven Weiss of QUEST and Associates for making the data available for analysis, Robert M. O'Brien (University of Oregon) for helpful comments, and Stephen du Toit of Scientific Software for technical assistance.

\section{REFERENCES}

Ajzen, I., \& Fishbein, M. (1980). Understanding attitudes and predicting social behavior. Englewood Cliffs, NJ: Prentice Hall.

Allport, G. W. (1961). Pattern and growth in personality. New York: Holt, Rinehart, \& Winston.

Anderson, J. C., \& Gerbing, D. W. (1988). Structural equation modeling in practice: A review and recommended two-step approach. Psychological Bulletin, 103, 411-423.

Ball-Rokeach, S. J., Rokeach, M., \& Grube, J. (1984). The great American values test: Influencing behavior and belief through television. New York: Free Press.

Bearden, W. O., \& Etzel, M. O. (1982). Reference group influence on product and brand purchase decisions. Journal of Consumer Research, 9, 183-194.

Bearden, W. O., Netemeyer, R. G., \& Teel, J. E. (1989). Measurement of consumer susceptibility to interpersonal influence. Journal of Consumer Research, 15, 473-481. 
Bearden, W. O., Netemeyer, R. G., \& Teel, J. E. (1990). Further validation of the consumer susceptibility to interpersonal influence scale. In M. E. Goldberg, G. Gorn, \& R. W. Pollay (Eds.), Advances in consumer research (Vol. 17, pp. 770-776). Provo, UT: Association for Consumer Research.

Bollen, K. A. (1989). Structural equations with latent variables. New York: Wiley.

Bourne, F. S. (1957). Group influence in marketing and public relations. In R. Likert \& S. P. Hayes (Eds.), Some applications of behavioral research (pp. 207-257). Paris: UNESCO.

Cronbach, L. J., \& Meehl, P. E. (1955). Construct validity in psychological tests. Psychological Bulletin, 52, 281-302.

Crosby, L. A., Gill, J. D., \& Lee, R. E. (1984). Life status and age as predictors of value orientation. In R. E. Pitt, Jr., \& A. G. Woodside (Eds.), Personal values and consumer psychology (pp. 201-218). Lexington, MA: Lexington.

Cox, D., \& Bauer, R. A. (1964). Self-confidence and persuasibility in women. Public Opinion Quarterly, 28, 453-466.

Dietz, T., \& Stern, P. C. (1995). Toward a theory of choice: Socially embedded preference construction. Journal of Socio-Economics, 24, 261-279.

Digman, J. M., \& Inouye, J. (1986). Further specification of five robust factors of personality. Journal of Personality and Social Psychology, 50, 116-123.

Eysenck, H. J. (1967). The biological basis of personality. Springfield, IL: Thomas.

Feather, N. T. (1975). Values in education and society. New York: Free Press.

Feather, N. T. (1993). Values and culture. In W. J. Lonner \& R. Malpass (Eds.), Psychology and culture (pp. 183-189). Boston: Allyn \& Bacon.

Feather, N. T. (1996). Values, deservingness, and attitudes toward high achievers: Research on tall poppies. In C. Seligman, J. M. Olson, \& M P. Zanna (Eds.), The psychology of values: The Ontario Symposium (Vol. 8, pp. 215-251). Mahwah, NJ: Lawrence Erlbaum Associates, Inc.

Fishbein, M., \& Ajzen, I. (1975). Belief, attitude, intention and behavior: An introduction to theory and research. Reading, MA: Addison-Wesley.

Ford, G. T., Smith, D. B., \& Swasy, J. L. (1990). Consumer skepticism of advertising claims: Testing hypotheses from economics of information. Journal of Consumer Research, 16, 433-441.

Fornell, C., \& Larcker, D. F. (1981). Evaluating structural equation models with unobservable variables and measurement error. Journal of Marketing Research, 18, 39-50.

Goodhead, V. (1991, December 9), Marketing to mature adults requires a state of being. Marketing News, p. 10.

Herche, J. (1994). Measuring social values: A multi-item adaptation to the list of values (Report No. 94-101). Boston: Boston Marketing Science Institute.

Homer, P. M., \& Kahle, L. R. (1988). A structural equation test of the value-attitude-behavior hierarchy. Journal of Personality and Social Psychology, 54, 638-646.

Izard, C. E. (1977). Human emotions. New York: Plenum.

Joachimsthaler, E. A., \& Lastovicka, J. L. (1984). Optimal stimulation level-Exploratory behavior models. Journal of Consumer Research, 1I, 830-835.

Jöreskog, K. G., \& Sörbom, D. (1993). LISREL 8 user's reference guide. Chicago: Scientific Software

Kahle, L. R. (Ed.). (1983). Social values and social change: Adaptation to life in America. New York: Praeger.

Kahle, L. R. (1996). Social values and consumer behavior: Research from the List of Values. In C. Seligman, J. M. Olson, \& M. P. Zanna (Eds.), The psychology of values: The Ontario Symposium (Vol. 8, pp. 135-151). Hillsdale, NJ: Lawrence Erlbaum Associates, Inc.
Kahle, L. R., Beatty, S. E., \& Homer, P. M. (1986). Alternative measurement approaches to consumer values: The List of Values (LOV) and Values and Lifestyles (VALS). Journal of Consumer Research, 13, 405-409.

Kahle, L. R., Kulka, R. A., \& Klingel, D. M. (1980). Low adolescent self-esteem leads to multiple interpersonal problems: A test of social adaptation theory. Journal of Personality and Social Psychology, 39, 492-502.

Kamakura, W. A., \& Novak, T. P. (1992). Value-system segmentation: Exploring the meaning of LOV. Journal of Consumer Research, 19, 119-132.

Katz, D. (1960). The functional approach to the study of attitudes. Public Opinion Quarterly, 24, 163-204.

Kelman, H. C. (1961). Processes of opinion change. Public Opinion Quarterly, 25, 57-78.

Kennedy, P. F, Best, R. J., \& Kahle, L. R. (1988). An alternative method for measuring value- based segmentation and advertising positioning. In L. H. James \& C. R. Martin, Jr. (Eds.), Current issues and research in advertising (Vol. 11, pp. 139-155). Ann Arbor, MI: Division of Research, Graduate School of Business Administration, University of Michigan.

Kristiansen, C. M., \& Zanna, M. P. (1992). The rhetorical use of values to justify social and intergroup attitudes. Joturnal of Social Issues, 50 , $47-65$.

Long, J. S. (1983). Covariance structure models: An introduction to LISREL. Beverly Hills, CA: Sage.

Lydon, J. E., \& Zanna, M. P. (1990). Commitment in the face of adversity: A values-affirmation approach. Journal of Personality and Social Psychology, 58, 1040-1047.

MacKenzie, S. B., \& Lutz, R. J. (1989). An empirical examination of the structural antecedents of attitude toward the ad in an advertising pretesting context. Journal of Marketing, 53, 48-65.

McGuire, W. J. (1968). Personality and susceptibility to social influence. In E. F. Borgatta \& W. W Lambert (Eds.), Handbook of personality theory and research (pp. 1130-1187). Chicago: Rand McNally.

Miniard, P. W., \& Cohen, J. B. (1979). Isolating attitudinal and normative influences in behavioral intentions models. Journal of Marketing Research, 16, 102-110.

Mulaik, S. A., James, L. R., Alstine, J. V., Bennett, N., Lind, S., \& Stilwell, C. D. (1989). Evaluation of goodness-of-fit indices for structural equation models. Psychology Bulletin, 105, 430-445.

Park, C. W., \& Lessig, P. V. (1977). Students and housewives: Differences in susceptibility to reference group influence. Journal of Consumer Research, 4, 102-1 10.

Prakash, V. (1984). Personal values and product expectations. In R. E. Pitts, Jr., \& A. G. Woodside (Eds.), Personal values and consumer psychology (pp. 145-154). Lexington, MA: Lexington.

Reynolds, T., \& Gutman, J. (1988). Laddering theory, method, analysis and interpretation. Journal of Advertising Research, 28, 11-31.

Rokeach, M. (1973). The nature of human values. New York: Free Press.

Schachter, S. (1971). Emotion, obesity, and crime. New York: Academic.

Schwartz, S. H. (1992). Universals in the content and structure of values: Theoretical advances and empirical tests in 20 countries. In M. P. Zanna (Ed.), Advances in experimental social psychology (Vol. 25, pp. 1-65). Orlando, FL: Academic.

Schwartz, S. H., \& Bilsky, W. (1987). Toward a universal psychological structure of human values. Journal of Personality and Social Psychology, 53, 550-562.

Seligman, C., Olson, J. M., \& Zanna, M. P. ( Eds.). (1996), The psychology of values: The Ontario Symposium (Vol. 8). Mahwah, NJ: Lawrence Erlbaum Associates, Inc.

Snyder, M. (1974). Self-monitoring of expressive behavior. Journal of Personality and Social Psychology, 30, 526-537. 
Stern, P. C., Dietz, T., Kalof, L., \& Guagnano, G. A. (1995). Values, beliefs and proenvironmental action: Attitude formation toward emergent attitude objects. Journal of Applied Social Psychology, 25, $1611-1636$

Valette-Florence, P., \& Jolibert, A. (1990). Social values, A.I.O., and consumption patterns. Journal of Business Research, 20, 109-122.

Vinson, D. E., Scott, J. E., \& Lamont, L. M. (1977). The role of personal values in marketing and consumer behavior. Journal of Marketing, 41, 44-50.
Werts, C. E., Linn, R. L., \& Joreskog, K. G. (1974). Interclass reliability estimates: Testing structural assumptions. Educational and Psychological Measurement, 34, 25-33.

Accepted by Curtis Haugtvedt. 